\title{
Mudanças no Cone Sul? Uma análise comparativa dos perfis materialista e pós-
}

\section{materialista}

\author{
Changes in the Southern Cone? A comparative analysis of the materialist and post-materialist \\ profiles \\ ¿Cambios en el Cono Sur? Un análisis comparativo de los perfiles materialista y posmaterialista
}

Recebido: 09/11/2021 | Revisado: 14/11/2021 | Aceito: 01/12/2021 | Publicado: 11/12/2021

\author{
Gabriela Marise Oliveira Bonifácio \\ ORCID: https://orcid.org/0000-0001-5607-9481 \\ Escola Nacional de Ciências Estatística, Brasil \\ E-mail: gabriela.o.bonifacil@gmail.com \\ Angelita Alves de Carvalho \\ ORCID: https://orcid.org/0000-0002-9342-4181 \\ Escola Nacional de Ciências Estatística, Brasil \\ E-mail: angelita.carvalho@ibge.gov.br
}

\begin{abstract}
Resumo
O objetivo desse estudo é apresentar um panorama da teoria pós-materialista de Inglehart em quatro países do Cone Sul (Argentina, Brasil, Chile e Uruguai) discutindo o perfil dos indivíduos materialistas e pós-materialistas e suas mudanças ao longo do tempo. Para tanto, lançou-se mão de uma análise descritiva do perfil de indivíduos materialistas e pósmaterialistas segundo um conjunto de variáveis sociodemográficas, e, em seguida, estabeleceu-se um modelo logístico binomial para verificar a influência dessas variáveis na determinação de cada perfil. Utilizou-se dados da pesquisa World Value Survey em três momentos no tempo (décadas de 1990, 2000 e 2010). Os resultados mostram que as diferenças não são tão grandes entre os perfis, mas tendem a corroborar com a teoria de Inglehart. Os resultados contribuem, ainda, para compreender a relação entre o contexto em que o indivíduo se encontra e seus comportamentos e valores, principalmente em realidades desiguais como a América Latina.
\end{abstract}

Palavras-chave: Materialismo; Posmaterialismo; Inglehart; América Latina; World Value Survey.

\begin{abstract}
The objective of this study is to present an overview of Inglehart's post-materialist theory in four countries in the Southern Cone (Argentina, Brazil, Chile and Uruguay) discussing the profile of materialists and post-materialists and their changes over time. For this purpose we carried out a descriptive analysis of materialistic and post-materialistic individuals profiles according to a set of sociodemographic variables, and then we applied a binomial logistic model to verify the influence of these variables in determining each profile. We used data from the World Value Survey at three different moments in time (1990s, 2000s and 2010s). Contrary to what we expected, the results show that the differences among the profiles are not expressive although tend to corroborate the Inglehart theory. The results also contribute to understanding the relationship between the context in which an individual lives and his behaviors and values, especially in unequal realities such as Latin America.
\end{abstract}

Keywords: Materialism; Post-materialism; Inglehart; Latin America; World Value Survey.

\section{Resumen}

El objetivo de este estudio es presentar un panorama de la teoría posmaterialista de Inglehart en cuatro países del Cono Sur (Argentina, Brasil, Chile y Uruguay) discutiendo el perfil de materialistas y posmaterialistas y sus cambios a lo largo del tiempo. Para ello, se realizó un análisis descriptivo del perfil de los individuos materialistas y posmaterialistas según un conjunto de variables sociodemográficas, y luego se estableció un modelo logístico binomial para verificar la influencia de estas variables en la determinación de cada perfil. Los datos de la Encuesta sobre el valor mundial se utilizaron en tres momentos (décadas de 1990, 2000 y 2010). Los resultados muestran que las diferencias no son tan grandes entre los perfiles, pero tienden a corroborar con la teoría de Inglehart. También contribuyen a comprender la relación entre el contexto en el que se encuentra el individuo y sus comportamientos y valores, especialmente en las realidades. desigual como la América Latina.

Palabras clave: Materialismo; Posmaterialismo; Inglehart; América Latina; World Value Survey. 


\section{Introdução}

A Região da América Latina está vivenciando mudanças importantes em sua dinâmica populacional, principalmente entre os estratos de elevada escolaridade e renda. Fenômenos que começam a despontar atualmente no cenário latino-americano (como a ruptura entre sexualidade e procriação e o aumento das uniões livres, por exemplo) já foram verificados em países europeus, como França, Noruega e Holanda, na segunda metade do século XX. Na época, a combinação de transformações nas esferas sociais, políticas, econômicas e culturais, levou a uma mudança do comportamento dos indivíduos em direção a uma maior satisfação pessoal. Isso quer dizer que, para além do cálculo econômico racional, a população desses países passou a se caracterizar pelo elevado grau de individualismo, já que as pessoas estavam buscando a auto-satisfação e autonomia, em detrimento do comportamento coletivo guiado por ideologias sustentadas pela Igreja e pelo Estado (van de Kaa, 1987 e 2001 ; Inglehart, 1997; Lesthaeghe, 2014).

Essa mudança ficou conhecida como pós-modernização, e tem no pós-materialismo o seu grande gatilho. Ronald Inglehart (1990; 1997), principal expoente e defensor da ideia pós-materialista, explica que ela abrange um conjunto de metas relacionadas a autoexpressão, a autonomia e ao bem-estar coletivo, que é buscado após alcançada a segurança material. O pósmaterialismo desenvolveu-se primeiramente nas sociedades pós-industriais modernas, europeias em sua maioria, onde as necessidades materiais básicas já estavam satisfeitas em sua quase plenitude. Nessas sociedades, a tendência era de maior tolerância às diferenças de gênero, à homossexualidade, ao aborto, às uniões livres (Inglehart, 1997).

$\mathrm{Na}$ América Latina, o contexto parece ser um pouco mais complexo, pois, se por um lado, algumas dessas transformações importantes, observadas em outros contextos, começam a manifestar-se, como o aumento das taxas de divórcio e de uniões livres (Nathan et al., 2016; Bonifácio, 2016; Cavenaghi \& Alves, 2009), por outro lado, ainda tem-se a persistência de valores tradicionais e poucos avanços em pautas em relação à temas e legislações importantes que acompanham essas tendências, tais como educação sexual, homossexualidade e aborto (Machado \& Graupe, 2016; Miguel et al., 2017).

Assim, na América Latina, e no Brasil em especial, o pós-materialismo ainda é bastante incipiente, alcançando parcela muito pequena da população. Mesmo assim, há estudiosos que dedicam-se a pesquisar esse fenômeno na Região, como é o caso de Ednaldo Ribeiro. Os estudos de Ribeiro são bastante valiosos para entender a difusão do pós-materialismo e sua manifestação entre os latino-americanos, com destaque para os brasileiros, no campo da política. Okado e Ribeiro (2017) também citam trabalhos que exploram o pós-materialismo sob a perspectiva de gênero e de movimentos ambientais. Contudo, ainda há uma demanda por trabalhos voltados para uma caracterização do perfil que distingue o indivíduo pós-materialista do indivíduo materialista, e para entender se as características que os definem atualmente são as mesmas encontradas em períodos anteriores. Ou seja, não há estudos voltados especificamente para identificar quem são os indivíduos materialistas e pós-materialistas, suas características socioeconômicas, demográficas, culturais, no contexto latino-americano.

Nesse sentido, o objetivo principal aqui proposto é apresentar um panorama do índice de pós-materialismo, desenvolvido por Inglehart (1990; 1997), em diferentes momentos no tempo, segundo algumas características selecionadas. Em particular, intenta-se observar se o percentual de pessoas classificadas como pós-materialistas aumentou ao longo do tempo e se elas apresentam perfil sociodemográfico distinto e exibem opiniões diferentes em relação aos temas selecionados, comparativamente aos indivíduos materialistas. Dessa maneira, acredita-se que será possível comprovar se os valores pósmaterialistas estão se difundindo nos países e se vêm acompanhados de mudança rumo a uma maior tolerância e liberdade, contribuindo para o delineamento de uma nova realidade latino-americana.

A metodologia empregada consiste, primeiramente, em uma análise descritiva de um conjunto de variáveis ligadas às características socioeconômicas e demográficas. Tais variáveis serão confrontadas com o índice pós-materialista, de maneira a captar especificidades entre indivíduos materialistas e pós-materialistas. A análise dar-se-á em três momentos distintos no tempo (décadas de 1990, 2000 e 2010), possibilitando captar a evolução do perfil da população no que diz respeito a esses aspectos. 
Em um segundo momento, essas variáveis, juntamente com aquelas sobre a opinião das pessoas quanto a alguns aspectos ligados à sexualidade, reprodução e nupcialidade, serão relacionadas ao índice de pós-materialismo em um modelo logístico binomial, de modo a captar as diferenças na determinação dos indivíduos como materialistas ou pós-materialistas. Para tanto, se lançará mão dos dados da pesquisa World Value Survey (WVS), a mais completa a tratar do tema proposto.

\section{Metodologia}

\subsection{A Base de dados: World Value Survey}

A fim de alcançar o objetivo proposto, lançou-se mão dos dados produzidos pelo projeto World Value Survey (WVS), que constitui-se de uma rede global de cientistas sociais que buscam pesquisar a mudança de valores e seu impacto na vida social e política em diversos países. Essa pesquisa é viabilizada por meio da realização de surveys a amostras nacionais usando um questionário padrão aplicado a homens e mulheres com idade acima de 18 anos.

A seleção dos países e a determinação das ondas da pesquisa basearam-se na disponibilidade dos dados e no atendimento à exigência de os países serem aqueles que estão mais avançados socioeconomicamente, pois, segundo o pressuposto de Inglehart, somente com o desenvolvimento socioeconômico é que o pós-materialismo pode surgir e se difundir. Assim, os países selecionados são todos pertencentes ao Cone Sul: Argentina, Brasil, Chile e Uruguai. No tocante às ondas de pesquisa, foram definidas aquelas que continham esses quatro países, porém com intervalo temporal mais ou menos uniforme entre elas: onda 3 (1995-1997); onda 5 (2006) e onda 6 (2011-2014), a última realizada.

Apesar de ser uma pesquisa representativa dos países e, por isso, de grande utilidade para comparações internacionais, o tamanho amostral é um complicador da WVS. Nos quatro países selecionados, a amostra, nas três ondas analisadas, possuía cerca de 1000 casos, com somente o Brasil apresentando um tamanho um pouco maior. Nesse sentido, na tentativa de amenizar o problema e aumentar o tamanho amostral, os dados referentes a cada país foram agrupados em uma única base de dados, por onda de pesquisa.

\subsection{0 Índice de pós-materialismo de Inglehart}

O perfil das pessoas materialistas e pós-materialistas foi delineado segundo características socioeconômicas, demográficas e em relação a alguns temas ligados à sexualidade, reprodução e nupcialidade. Para tanto, utilizou-se o índice criado por Inglehart (1997) para classificar os entrevistados como materialistas e pós-materialistas. Nesse estudo, tal índice ficou denominado de índice de pós-materialismo, por questões didáticas. O desenvolvimento desse índice passou por modificações até se estabelecer, atualmente, com 12 itens que o compõem.

Além das modificações sofridas ao longo do tempo, que culminou num índice composto por 12 itens, outras medidas foram elaboradas a fim de suprir as deficiências na medida inicial proposta por Inglehart. Nesse sentido, Inglehart e Welzel (2005) desenvolveram o índice de autoexpressão, como alternativa ao índice de pós-materialismo. Posteriormente, conforme Okado e Ribeiro (2017, p. 11), Welzel apresenta o índice de valores emancipatórios, como uma proposta de revisão da teoria de mudança valorativa, servindo como métrica para avaliar a relação entre desenvolvimento, mudança valorativa e democratização. Esses índices alternativos, conquanto possam representar algumas melhorias, em relação ao índice pós-materialista, também possuem limitações e não o substituem, além de não expressarem a teoria pós-materialista de Inglehart, tal como o índice original. Grande parte da literatura sobre o assunto utiliza o índice de pós-materialismo clássico, de modo que o emprego desse índice, ao invés dos alternativos, permite uma comparação maior com outros trabalhos. Assim, o índice de pós-materialismo baseia-se no conjunto de respostas do entrevistado a esses 12 itens que representam as prioridades de uma sociedade. A seguir, apresenta-se o Quadro 1, no qual há a distribuição dos itens conforme os parâmetros materialista e pós-materialista: 
Quado 1. Distribuição dos doze itens presentes no índice de pós-materialismo, segundo seu conteúdo materialista ou pósmaterialista.

\begin{tabular}{|l|l|}
\hline \multicolumn{1}{|c|}{ Materialismo } & \multicolumn{1}{c|}{ Pós-materialismo } \\
\hline 1. manter a ordem & 1. maior participação do cidadão nas decisões do governo \\
2. lutar contra o aumento dos preços & 2. proteger a liberdade de expressão \\
3. manter altas taxas de crescimento econômico & 3. importância da opinião sobre empregos e comunidades \\
4. assegurar fortes forças de defesa & 4. embelezar cidades e campos \\
5. manter economia estável & 5. progredir em direção a uma sociedade mais humana \\
6. lutar contra a criminalidade & 6. sociedade onde as ideias contam mais que o dinheiro \\
\hline
\end{tabular}

Fonte: Inglehart (1997, p. 119); Ribeiro (2009).

Os entrevistados são classificados conforme a escolha prioritária e secundária de itens para cada bateria de questões, cujo resultado final é distribuído em uma escala de zero a cinco. Assim, são classificados como materialistas (escala 0) os entrevistados que priorizam os itens ligados exclusivamente ao materialismo. Os que se encontram na escala 1 são aqueles que escolhem, preferencialmente, os itens relacionados ao materialismo, mas não todos. Os indivíduos na escala 2 e 3 são os que apresentam maior variação na ordem de priorização dos itens e, por isso, são classificados como mistos. Os que estão na escala 4 são aqueles que tendem a priorizar os itens relacionados ao pós-materialismo, mas não em todas as questões. Os entrevistados classificados como pós-materialistas (escala 5) são os que escolhem itens prioritários que se referem unicamente ao pósmaterialismo. Nesse estudo, a escala de classificação foi ajustada a fim de facilitar as análises dos resultados. Dada a proximidade dos entrevistados classificados como 0 e 1, eles foram agregados como materialistas; pessoas classificadas como 2 e 3 permaneceram como mistas e os entrevistados classificados como 4 e 5 , por sua proximidade de valores e prioridades, foram agregados como pós-materialistas, ficando o índice dividido em apenas três categorias. Acredita-se que, ao realizar tal reagrupamento, o índice não é alterado em sua essência, uma vez que foram colocados, sob uma mesma denominação, indivíduos que apresentam tendências muito próximas. E isso foi feito tentando minimizar o problema de tamanho amostral, haja vista o baixo número de pessoas classificadas como pós-materialistas nos países selecionados. Desse modo, embora tal ajuste afete a escala do índice pós-materialista, ele não interfere em sua construção e propósito, pelo contrário, aumentou a representatividade dos grupos, melhorando as análises. Daí, acredita-se que, mesmo alterado para apenas três categorias, o índice pós-materialista ainda cumpre satisfatoriamente seu objetivo, o que justifica seu emprego. Após algumas análises iniciais, decidiu-se trabalhar apenas com os dois grupos extremos, focando a discussão na dualidade entre indivíduos materialistas e pós-materialialistas e captar as suas distinções, excluindo as pessoas classificadas como mistas, uma vez que seus perfis não puderam ser relacionados a nenhum posicionamento valorativo específico.

Apesar do refinamento metodológico ao longo da sua construção, o índice de pós-materialismo ainda sofre questionamentos e críticas sobre sua eficácia como medida de valores individuais (Van Deth, 1983; Musa, 2006; Eklund, 2012). No entanto, esse estudo não tem por meta avaliar esses aspectos críticos em relação ao índice, nem mesmo pretende testar sua qualidade. Existem estudos disponíveis que trataram dessa questão inclusive para a América Latina (Ribeiro, 2007; Okado e Ribeiro, 2017), com Ribeiro (2007), por meio de testes estatísticos, confirmando sua consistência para o contexto latinoamericano.

\subsection{As variáveis socioeconômicas, demográficas e valorativas}

As variáveis socioeconômicas e demográficas selecionadas foram: classe social, escolaridade, idade, sexo, religião, se o entrevistado tinha trabalho remunerado na data da pesquisa, número de filhos que o entrevistado tinha na data da pesquisa e status marital. Elas foram recodificadas de maneira a atender aos objetivos desse estudo.

No caso das variáveis ligadas à sexualidade, reprodução e nupcialidade, cabe aqui um pequeno comentário. O 
questionário da pesquisa WVS traz uma variedade de temas sobre os quais os entrevistados são levados a se posicionarem/opinarem, contudo, no tocante a esse módulo, infelizmente, a WVS contém apenas variáveis que buscam captar o posicionamento do entrevistado sobre homossexualidade, aborto e divórcio, e que foram, portanto, utilizadas nas análises mediante processo de recodificação. Assim, reconhece-se a limitação do estudo no tocante a esse aspecto, em decorrência da escassez de dados na WVS. Juntamente a essas variáveis, também utilizou-se uma variável ligada à valores de gênero, por julgar que estes estão bem próximos dos mencionados anteriormente. As opiniões concernentes à variável "a satisfação da mulher como dona de casa é igual à satisfação como sendo trabalhadora assalariada" foram recategorizadas em duas categorias (concorda e discorda, seja total ou parcialmente).

Ainda no que diz respeito às variáveis, menciona-se os casos missing. Quase todas as variáveis estudadas possuíam algum grau de não resposta ou resposta inconsistente, que foram classificadas como missing. Embora, em algumas ocasiões, o número de missing fosse elevado, não chegou a $10 \%$ do total de observações para cada variável, dessa forma, não houve tratamento para os casos missing, eles foram excluídos das bases de dados.

\subsection{O modelo logístico}

A fim de verificar a relação e influência das variáveis estudadas e o índice de pós-materialismo, foi adotado o modelo de regressão logística binomial. Com base nas orientações de Hosmer e Lemeshow (1989), o modelo binomial é aquele em que a variável resposta possui apenas duas categorias. Desse modo, tendo em vista que, no presente estudo, a variável resposta é a distribuição dos indivíduos segundo o índice de pós-materialismo modificado, o modelo permite perceber as possíveis diferenças no grupo dos indivíduos materialistas (categoria de referência) e pós-materialistas a partir de todas as variáveis de interesse. Após alguns testes, houve a necessidade de recodificar algumas das variáveis, a fim de melhor compor o modelo estatístico. Foram os casos da variável renda, que foi utilizada em substituição à classe social, uma vez que esta variável apresentou colinearidade com escolaridade, e número de filhos, que foi renomeada para "presença de filhos". Estas variáveis foram reclassificadas em apenas duas categorias devido à não significância estatísticas de todas as categorias separadas. Após algumas análises, aquelas variáveis que não deram significativas foram retiradas do modelo, tais como classe social, trabalho na semana de referência e sexo, contudo, optou-se por deixar outras que, mesmo não sendo significativas, são de interesse do estudo, tais como presença de filhos e estado conjugal. Para essa seleção, e exclusão de variáveis, também levou-se em consideração a parcimônia do modelo.

\section{Resultados e Discussões}

\subsection{Mudanças no contingente de materialistas, pós-materialistas e mix, nos quatro países analisados.}

A Tabela 1 apresenta a evolução do percentual de indivíduos materialistas, mix e pós-materialistas nos quatro países selecionados, em diferentes pontos no tempo, segundo as ondas realizadas das pesquisas WVS. A fim de compreender as mudanças que ocorreram nesses percentuais ao longo do tempo, faz-se necessário conhecer o contexto dos países nas épocas de realização de cada onda selecionada, pois, segundo a teoria de Inglehart, o surgimento e desenvolvimento de valores pósmaterialistas, em detrimento dos valores materialistas, sofre influência do contexto socioeconômico no qual o indivíduo está inserido.

Assim, a América Latina passou por transformações desde a década de 1980 até meados da década de 2010. Os países do Cone Sul, analisados nesse estudo, são bons representantes dessas mudanças, principalmente porque Argentina, Brasil, Chile e Uruguai experimentaram crises políticas e econômicas semelhantes. Os quatro países vivenciaram período de ditadura militar, que finalizou em 1973 na Argentina, em 1985 em Brasil e Uruguai, e um pouco mais tarde no Chile - 1990. A presença de um 
Estado forte, ativo e com relativa autonomia em relação à sociedade ofereceu condições para o surgimento e desenvolvimento de políticas de liberalização econômica, proporcionando a chegada de investimentos internacionais (Sola, 1995).

As mudanças provocadas pela nova realidade neoliberal, assim como no campo social, nem sempre foram positivas no campo econômico. O Brasil, por exemplo, passou por um período bastante turbulento entre meados de 1980 e 1990, atingindo diretamente a população: inflação elevada, crises econômicas, déficit público e dívida externa foram algumas características que marcaram esse período (Pinheiro et al., 1999). O Chile também sofreu um período de crise econômica, que deteriorou políticas de bem-estar social, porém, esse período foi relativamente mais curto do que foi no Brasil. Assim, já na década de 1990, durante o período de reestabelecimento democrático, além do crescimento econômico importante, o Chile passou a ocupar as primeiras posições da América Latina em todos os indicadores de desenvolvimento econômico e social (Larrañaga, 2010, p.56-57).

Argentina e Uruguai vivenciaram situação semelhante. A Argentina experimentou uma fase de recuperação econômica entre 1991 e 1993, com crescimento do PIB e melhoria da maioria dos indicadores macroeconômicos (Salvia \& Tissera, 2002). Em seguida, a economia começou a dar sinais de um enfraquecimento e instabilidade; entre 1996 e 1998 houve uma superação dessa etapa crítica, com crescimento interno e expansão das exportações (Salvia \& Tissera, 2002, p. 87-88). O Uruguai, por sua vez, atravessou uma fase de crescimento econômico importante entre 1986 e 1994. Sofreu uma recessão em 1995, mas já em 1996 conseguiu recuperar-se. Foi na década de 90 que o processo de liberalização comercial solidificou-se no país, e o salário real e o emprego formal aumentaram, além de haver uma maior qualificação da força de trabalho (Vigorito, 1999, p. 248-249).

Baseando-se na premissa de Inglehart de que o contexto socioeconômico tem relação com o surgimento e estabelecimento dos ideais pós-materialistas, a breve descrição da situação dos países selecionados, entre as décadas de 80 e 90 , ajuda a entender os percentuais de materialistas e pós-materialistas na terceira onda da pesquisa WVS, realizada nessa época, conforme a Tabela 2. O Brasil, que estava ainda em processo de recuperação da sua economia, e era um país muito desigual, foi aquele que apresentou o menor percentual de indivíduos pós-materialistas e o maior de materialistas. Os outros três países passavam por situação diferente. A Argentina, país com maior percentual de população pós-materialista e o de menor percentual materialista, vivenciava uma realidade de crescimento econômico. Além disso, tem se destacado, desde a época do regime militar, pela grande mobilização social e de crítica às instituições representativas tradicionais, nos moldes destacados por Inglehart (Ribeiro \& Borba, 2010).

Vale ressaltar, contudo, que o percentual de indivíduos pós-materialistas, nos quatro países analisados, na década de 90, era muito baixo comparativamente ao dos países mais desenvolvidos, europeus em sua maioria. Ribeiro e Borba (2010) sugerem que o baixo percentual de indivíduos pós-materialistas pode ser explicado pela distribuição desigual dos benefícios do crescimento econômico entre a população, prejudicando o desenvolvimento dos valores pós-materialistas que se difundiram apenas entre uma parcela pequena da população mais abastada, como já mencionado.

Na primeira década do século XXI, um novo cenário desponta na América Latina, especialmente nos quatro países analisados. O crescimento econômico observado no final dos anos 90 acelerou-se nos anos 2000, apesar de haver momentos de instabilidade, e até mesmo de crise, nessa época. No entanto, mesmo apresentando algum crescimento econômico e melhoria das condições de vida, os dados da Tabela 2 mostram que a proporção de indivíduos pós-materialistas diminuiu nos quatro países entre as décadas de 90 e 2000, e aumentou a proporção de materialistas (com exceção do Uruguai). Uma explicação para esse comportamento tem relação com os contextos dos países. A economia desses países tem se caraterizado, desde a implantação das políticas neoliberais, pela falta de continuidade, em que períodos de rápido crescimento são interrompidos por crises importantes, o que afeta as expectativas dos indivíduos quanto ao futuro. Ademais, a deterioração das condições de trabalho, o aumento das desigualdades sociais, além do fraco desempenho de muitas dessas políticas neoliberais de aumentar o poder de consumo interno da população e de promover um crescimento econômico satisfatório, pode ter levado a que parte dos indivíduos, que tinha perfil pós-materialista, mudasse seus valores. Esse cenário, inclusive, ofereceu as condições para o surgimento do 
fenômeno da ascensão ao poder de governos de centro-esquerda na América Latina, incluindo nos quatro países analisados, como alternativas aos debilitados governos neoliberais. Assim, nas décadas de 2000 e 2010, houve mudança do papel do Estado; ênfase e redesenho das políticas sociais; ampliação da participação social no governo e uma busca de maior autonomia em relação a organismos internacionais (da Silva, 2015). O Uruguai, por exemplo, país com larga tradição democrática, e que já havia adotado a jornada de 8 horas de trabalho; aprovada a lei do divórcio e estabelecido o voto feminino antes mesmo de países europeus (Sader, 2006), por sua vez, foi o primeiro país do mundo a legalizar a produção e o comércio da maconha (2013); e o segundo país a aprovar o "matrimônio igualitário" na América do Sul (2013); também esteve entre os primeiros latinoamericanos a legalizar o aborto (2012) (Burni et al., 2014). E todas essas mudanças ocorreram no país nas primeiras décadas do século XXI. Já no caso do Chile, houve uma redefinição das políticas sociais em duas fases, conforme Larrañaga (2010, p. 57): a primeira fase seria aquela de quitação da dívida social, em que os recursos fiscais foram destinados para áreas sociais com déficit acumulado - educação, saúde, moradia, por exemplo; a segunda fase foi marcada pela mudança estrutural das políticas sociais, garantindo a cobertura dos benefícios sociais a grupos ampliados da população. Essas realidades ajudam a entender o fato de o Chile ter aumentado a proporção de indivíduos pós-materialistas entre as décadas de 2000 e 2010, tornando-se o país de maior contingente pós-materialista, dos quatro analisados, e do Uruguai praticamente manter o percentual de pósmaterialistas, situando-se logo atrás do Chile (Tabela 1).

Tabela 1. Percentual de indivíduos classificados como materialistas, mix e pós-materialistas, em diferentes momentos do tempo. Argentina, Brasil, Chile e Uruguai. WVS, ondas 3, 5 e 6.

\begin{tabular}{|c|c|c|c|c|c|c|}
\hline \multirow{2}{*}{$\begin{array}{c}\text { Onda da Pesquisa } \\
\text { WVS }\end{array}$} & \multirow{2}{*}{ País e ano } & \multirow{2}{*}{$\frac{\text { Materialismo }}{\%}$} & \multirow{2}{*}{$\frac{\text { Mix }}{\%}$} & \multirow{2}{*}{$\begin{array}{c}\text { Pós-materialismo } \\
\%\end{array}$} & \multicolumn{2}{|c|}{ Total } \\
\hline & & & & & $\mathrm{N}$ & $\%$ \\
\hline \multirow{5}{*}{3} & Argentina - 1995 & 17,3 & 54,0 & 28,7 & 1040 & 100,0 \\
\hline & Brasil - 1997 & 27,7 & 60,8 & 11,5 & 1128 & 100,0 \\
\hline & Chile - 1996 & 19,8 & 61,8 & 18,4 & 968 & 100,0 \\
\hline & Uruguai - 1996 & 20,2 & 57,9 & 21,9 & 910 & 100,0 \\
\hline & Total & 21,5 & 58,7 & 19,9 & 4046 & 100,0 \\
\hline \multirow{5}{*}{5} & Argentina - 2006 & 33,9 & 52,7 & 13,4 & 902 & 100,0 \\
\hline & Brasil - 2006 & 31,5 & 59,5 & 9,0 & 1413 & 100,0 \\
\hline & Chile - 2006 & 24,2 & 60,2 & 15,6 & 947 & 100,0 \\
\hline & Uruguai - 2006 & 19,6 & 60,7 & 19,7 & 862 & 100,0 \\
\hline & Total & 27,9 & 58,4 & 13,7 & 4124 & 100,0 \\
\hline \multirow{5}{*}{6} & Argentina - 2013 & 32,6 & 57,6 & 9,8 & 966 & 100,0 \\
\hline & Brasil - 2014 & 31,7 & 59,4 & 8,9 & 1309 & 100,0 \\
\hline & Chile - 2012 & 21,5 & 55,8 & 22,7 & 962 & 100,0 \\
\hline & Uruguai - 2011 & 25,4 & 55,5 & 19,0 & 830 & 100,0 \\
\hline & Total & 28,2 & 57,3 & 14,4 & 4067 & 100,0 \\
\hline
\end{tabular}

Fonte: (Inglehart et al., 2014 a, b,c) - World Value Survey, ondas 3 (1995 - 1997), 5 (2006) e 6 (2011 - 2014).

\subsection{O perfil socioeconômico e demográfico dos indivíduos materialistas e pós-materialistas.}

A partir da análise de características demográficas (idade, sexo, número de filhos e status marital) 1, constatou-se que o perfil demográfico entre materialistas e pós-materialistas era muito parecido na onda 3 (1995-1996), de modo que a única variável que, de fato, os distinguia era o número de filhos tidos. Inclusive, as variáveis sexo e status marital apresentavam uma distribuição muito semelhante entre as duas classificações. Isso significa que, na época da realização da terceira onda da pesquisa WVS, somente características demográficas não eram capazes de distinguir pessoas materialistas daquelas pós-materialistas. No 
entanto, os dados mostram que o percentual de pós-materialistas jovens, com até 29 anos, era maior que o percentual de materialistas, e que os pós-materialistas solteiros estavam em maior proporção, em relação aos outros status maritais (casado, união consensual, divorciado/separado e viúvo), quando comparados com os materialistas. O perfil encontrado na onda 3 não parece ter se alterado ao longo do tempo, pois características semelhantes foram encontradas na onda 5 (2006) e na onda 6 (20112014).

As fases de instabilidade política e econômica, vivenciadas pelos países analisados nessas épocas, pode ser uma explicação plausível para o declínio de pós-materialistas jovens, por exemplo. Contudo, cabe salientar que esse declínio não foi compensado com o aumento de jovens materialistas, que também sofreu leve declínio entre as duas ondas. Na verdade, houve um aumento do peso dos grupos etários mais velhos entre os pós-materialistas. E isso é compreensível na medida em que se considera a perspectiva do ciclo de vida dos indivíduos. Conforme Inglehart, uma vez adquiridas, as orientações de valores pósmaterialistas permanecem mais ou menos estáveis ao longo da vida do indivíduo. Desse modo, boa parte dos jovens pósmaterialistas na onda 3 envelheceram e passaram a representar os indivíduos mais velhos nas ondas seguintes, sem que houvesse um crescimento do grupo mais jovem, para essas ondas.

Juntamente com o aspecto demográfico, analisou-se as características socioeconômicas dos indivíduos (escolaridade, classe social, religião e se o entrevistado possuía trabalho na data da pesquisa). De modo geral, não há grandes diferenças entre os dois grupos, no que tange à classe social. No entanto, sabe-se que o contexto socioeconômico influência nas mudanças valorativas. Nesse sentido, o declínio de indivíduos pós-materialistas da classe social mais alta, ao longo das ondas WVS, pode ter como explicação plausível mudanças que ocorreram no contexto dos países selecionados durante essas ondas, e que pode ter afetado o bem-estar e o sentimento de segurança desses indivíduos, fazendo com que diminuísse o seu contingente ao longo do tempo.

No que se refere à questão da religião, nota-se que, na onda 3, a presença de indivíduos religiosos é forte para ambos os grupos de valores, conquanto o percentual de materialistas religiosos fosse maior que o de pós-materialistas. Na onda 5, o cenário manteve-se parecido. Na onda 6, no entanto, observa-se que há um declínio no percentual indivíduos pós-materialistas religiosos (Tabela 2). Entre os materialistas, por outro lado, permaneceu a supremacia dos religiosos. O declínio dos pósmaterialistas religiosos indica a perda da influência da religião na vida dessas pessoas, e isso tem relação com o processo de secularização, peculiar às populações pós-modernas, em que há um remodelamento do papel da religião nas orientações individuais.

A escolaridade também é uma característica que guarda relação com o desenvolvimento de valores pós-materialistas. Assim, como esperado, entre os indivíduos pós-materialistas prevaleceram aqueles com escolaridade mais elevada, representada pela categoria "secundário e mais", nas três ondas WVS analisadas (Tabela 2). Entre os materialistas deu-se o contrário, com prevalência da categoria de escolaridade mais baixa, exceto na última onda (Tabela 2). Desse modo, assim como os resultados para a classe social, os resultados para escolaridade também estão coerentes com a teoria de Inglehart.

O fato de ter um trabalho remunerado também ajuda a entender a adoção de um determinado conjunto de valores. Considerando que os entrevistados que não tinham trabalho remunerado na data da pesquisa eram, possivelmente, os que não possuíam os meios adequados para satisfazer as demandas materiais básicas, isso pode explicar a diferença observada entre os dois grupos. De fato, conforme a Tabela 2, nas duas primeiras ondas, os indivíduos pós-materialistas exerciam, em sua maioria, algum tipo de trabalho remunerado, enquanto o contrário ocorria no grupo de materialistas. Na onda 6, contudo, nos dois grupos prevaleceram aqueles que trabalhavam com remuneração, apesar de a proporção entre os pós-materialistas fosse maior. 
Tabela 2. Percentual de indivíduos classificados como materialistas e pós-materialistas segundo características socioeconômicas. Argentina, Brasil, Chile e Uruguai. WVS, ondas 3, 5 e 6.

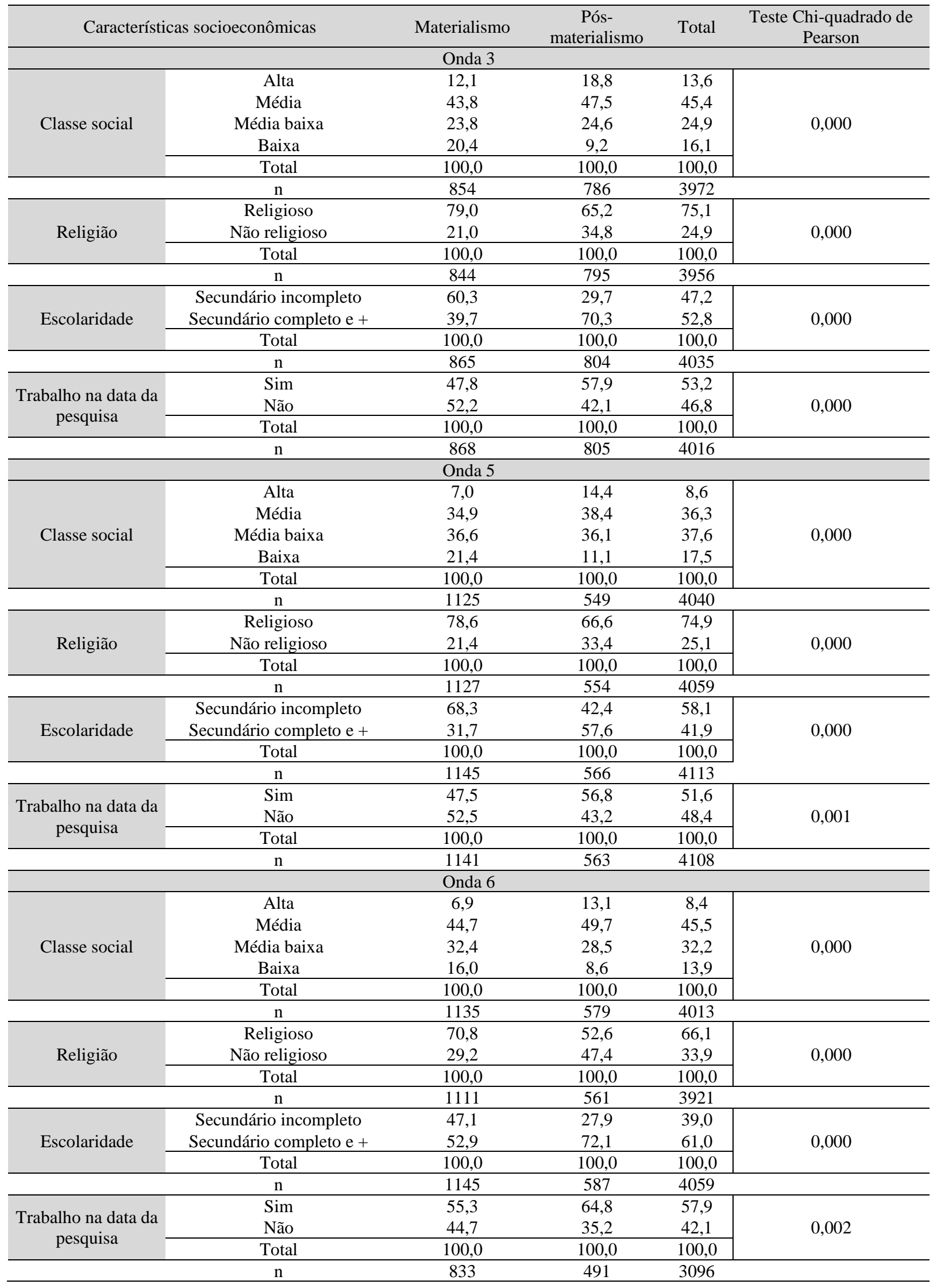

Nota: Teste de correlação de Pearson (Chi-Square) menor que 0,001 significância de $99 \%$, menor do que 0,005 significância de $95 \%$ e menor que 0,1 significância de 90\%. Fonte: (Inglehart et al., 2014 a, b,c) - World Value Survey, ondas 3 (1995 - 1997), 5 (2006) e 6 (2011 - 2014). 


\subsection{Posicionamento em relação a alguns valores dos indivíduos materialistas e pós-materialistas}

A Tabela 3 revela a mudança no posicionamento das pessoas classificadas como pós-materialistas em relação a alguns tópicos de sexualidade, reprodução e nupcialidade. Na onda 3, essas pessoas expressavam opiniões mais conservadoras, ou seja, com caráter de menor tolerância e aceitação em relação ao aborto e à homossexualidade e um pouco menos conservador quanto ao divórcio. Nas ondas seguintes, o posicionamento dos pós-materialistas altera-se, uma vez que houve um aumento dos percentuais nas categorias de resposta mais liberais, de maior tolerância, em detrimento da diminuição dos percentuais nas categorias de resposta com cunho mais conservador. No caso do aborto, por exemplo, conquanto nas três ondas prevalecessem aqueles que consideravam que o aborto era nunca ou quase nunca justificável, houve um aumento importante, ao longo do tempo, no percentual de indivíduos que consideravam que o aborto era sempre ou quase sempre justificável (Tabela 3). Em relação ao divórcio e à homossexualidade, metade, ou mais da metade, dos indivíduos pós-materialistas na onda 6 julgavam ser sempre ou quase sempre justificável, o que não acontecia na onda 3, cujos percentuais eram muito mais baixos nessa categoria (Tabela 3).

Nota-se que a principal mudança ocorreu na onda 6. E isso é justificável, pois foi durante os primeiros 15 anos do século XXI que a sociedade latino-americana discutiu livremente e participou mais ativamente de questões ligadas à legalização do aborto e aos direitos civis e conjugais de homossexuais, por exemplo. Enfim, a onda 6 captou uma mudança de valores e comportamentos em curso na sociedade latina, e os indivíduos pós-materialistas são os principais representantes dessa mudança. Daí apresentarem um posicionamento mais permissivo e tolerante concernente a esses temas, do que nas ondas anteriores. 
Tabela 3. Percentual dos indivíduos classificados como materialistas e pós-materialistas segundo alguns valores, Argentina, Brasil, Chile e Uruguai. WVS, ondas 3, 5 e 6.

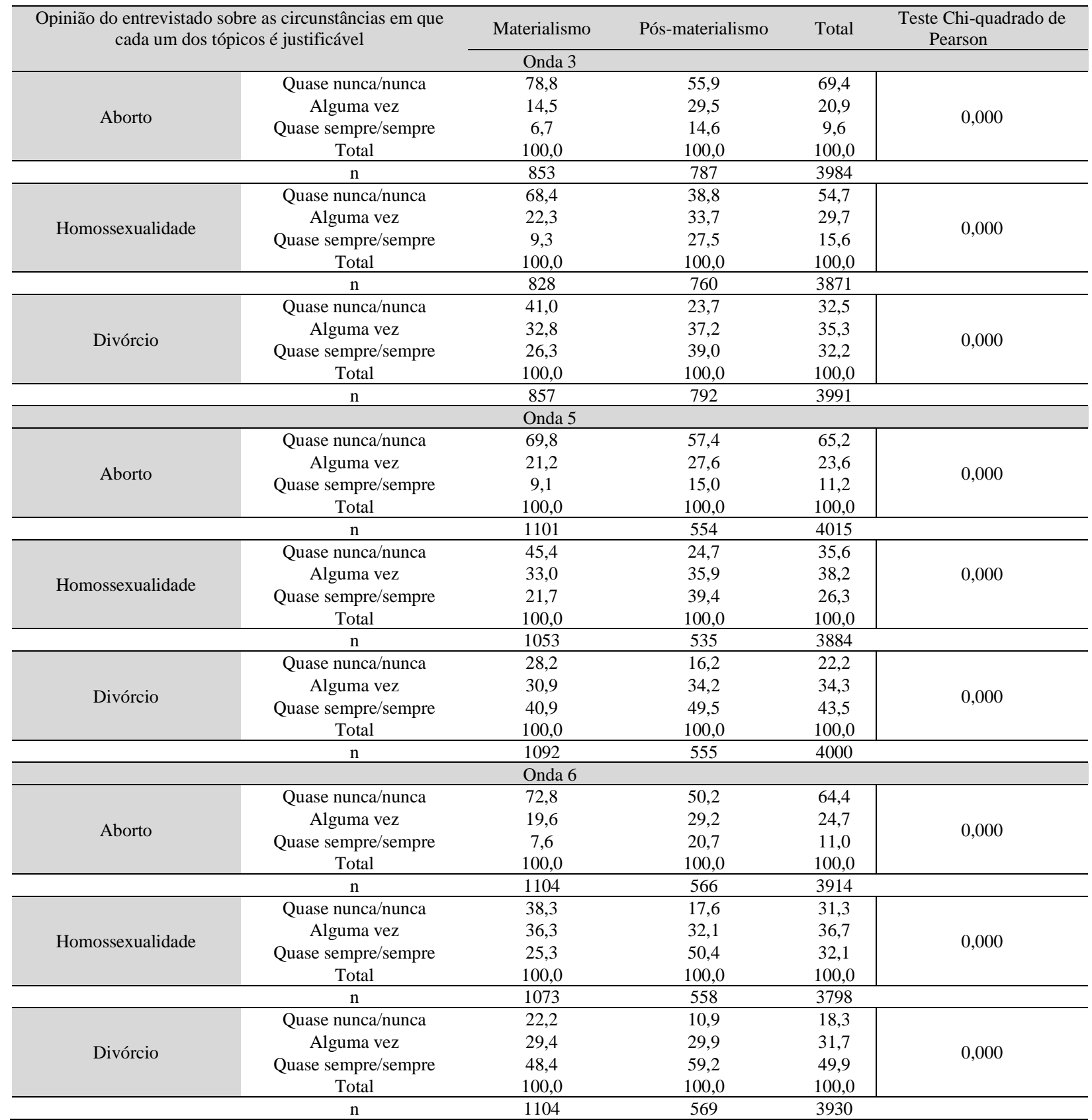

Nota: Teste de correlação de Pearson (Chi-Square) menor que 0,001 significância de 99\%, menor do que 0,005 significância de 95\% e menor que 0,1 significância de 90\%. Fonte: (Inglehart et al., 2014 a, b,c) - World Value Survey, ondas 3 (1995 - 1997), 5 (2006) e $6(2011-2014)$

\subsection{Resultados do modelo estatístico}

A Tabela 4 mostra detalhadamente os resultados da regressão logística para cada variável e suas categorias. Os resultados vistos aqui reforçam os dados da análise descritiva. Com relação ao país de residência, fica evidente que não ser brasileiro aumenta as chances do indivíduo ser pós-materialista, pois, como apresentado, o Brasil é o país que apresenta o menor percentual de pessoas pós-materialistas dos quatro analisados. Como já esperado, quanto mais jovem, maiores são as chances de o indivíduo ser pós-materialista. Na onda 6, por exemplo, um indivíduo de menos de 29 anos tinha $80 \%$ a mais de chance de ser pós-materialista quando comparado aos indivíduos de 50 anos e mais, mesmo com o percentual de jovens pós-materialistas ser 
menor nessa onda. Esses dados demonstram conformidade com o que preconiza Inglehart (1997) sobre a teoria do pósmaterialismo, em que esse fenômeno é mais fácil de ser observado entre os jovens, os quais são os primeiros a sentir os efeitos do desenvolvimento econômico, cultural e social em uma sociedade.

Quanto menor a escolaridade (Tabela 4), menor a chance de o indivíduo ser pós-materialista, sendo que, na última onda, isso chega a representar $50 \%$ a menos de chance para aqueles que tem menos que o ensino secundário quando comparados com aqueles que tem o secundário ou mais. No mesmo sentindo é o que ocorre com a renda: pessoas situadas até o $4^{\circ}$ decil de renda tem menos chance de serem pós-materialistas quando comparadas com aquelas situadas nos decis de renda mais altos. Interessante observar que estas duas variáveis parecem perder um pouco sua significância nas ondas mais recentes. O que pode estar relacionado ao efeito coorte ou contextual, como já mencionado. De qualquer forma, esses dados parecem confirmar a teoria de Inglehart de que os valores pós-materialistas são mais difundidos quando as necessidades materiais básicas são atendidas com segurança, o que ocorre de forma mais evidente entre pessoas com maior renda e escolaridade. Perspectiva similar também foi discutida em Macintosh (1998), para quem os níveis de escolaridade estão associados ao pós-materialismo, porque a educação é uma medida indireta da prosperidade da família. À medida que as gerações que se sucedem tornam-se economicamente mais seguras durante a primeira socialização, elas têm maior acesso à educação e tornam-se mais pósmaterialistas em suas atitudes. Já no que tange à religião, nota-se que aqueles que possuem alguma religião possuem menos chances de serem pós-materialistas quando comparados com aqueles sem religião. Esse resultado está de acordo com o estudo de Inglehart e Baker (2000), os quais consideram que pessoas de uma determinada sociedade que enfatizam a religião estão mais associadas a valores materialistas e menos a valores pós-materialistas.

A variável presença de filhos (Tabela 4) somente foi significativa na primeira onda, em que pessoas sem filhos tinham mais chances de serem pós-materialistas do que pessoas com filhos. Nas demais ondas, apesar de ir no mesmo sentido, a variável não foi estatisticamente significativa. Resultados similares foram encontrados no estudo de Van de Kaa (2001) para a Europa, o qual revela que existiria forte associação entre ter menos filhos, e tê-los mais tardiamente, e valores pós-materialistas. Estado conjugal não se mostrou significativa em nenhuma das ondas analisadas, apesar de estudos para os países europeus indicarem uma correlação forte entre o percentual de pessoas vivendo em união livre e pós-materialismo, por exemplo (Van de Kaa, 2001; Surkyn \& Lesthaeghe, 2004).

Com relação às variáveis de opinião do entrevistado, nota-se, de modo geral, que as pessoas que tendem a ser menos permissivas com relação ao aborto e à homossexualidade possuem menores chances de serem pós-materialistas. Para exemplificar, na onda 6, aquelas pessoas que declararam que o aborto nunca ou quase nunca deveria ser permitido apresentaram $37 \%$ menos de chances de serem pós-materialistas quando comparadas com aquelas que responderam que o aborto deveria ser sempre ou quase sempre permitido (Tabela 4).

Quanto à homossexualidade, percebe-se na tabela 4 que esses percentuais chegaram à $60 \%$. Os dados relativos ao divórcio, ainda na Tabela 4, são menos expressivos e nem sempre significativos, de modo que as opiniões sobre quando o divórcio deve ser permitido não são capazes de diferenciar os entrevistados entre materialistas e pós-materialistas. Contudo, em relação à variável de gênero, percebe-se que as pessoas que possuem uma opinião discordante sobre a satisfação da mulher como dona de casa ou trabalhadora assalariada tendem a apresentar menos chances de serem pós-materialistas do que aquelas que concordam. Uma possível explicação seria os indivíduos pós-materialistas terem, normalmente, uma visão mais igualitária sobre as relações de gênero e, portanto, entenderem que, de fato, uma mulher como dona de casa poderia ter tanta satisfação como quanto ela ser trabalhadora assalariada, já que isso pode significar uma livre escolha dela. Enquanto isso, entre os materialistas, predominaria uma perspectiva mais desigual, refletindo na opinião contrária sobre a satisfação da mulher. 
Research, Society and Development, v. 10, n. 16, e231101623075, 2021

(CC BY 4.0) | ISSN 2525-3409 | DOI: http://dx.doi.org/10.33448/rsd-v10i16.23075

Tabela 4. Resultado do modelo final de regressão logística para cada onda WVS. Argentina, Brasil, Chile e Uruguai. WVS, ondas 3 , 5 e 6.

\begin{tabular}{|c|c|c|c|c|c|c|c|c|c|c|}
\hline \multirow{2}{*}{\multicolumn{2}{|c|}{ Variáveis explicativas }} & \multicolumn{3}{|c|}{ Onda 3} & \multicolumn{3}{|c|}{ Onda 5} & \multicolumn{3}{|c|}{ Onda 6} \\
\hline & & Coeficiente & P-Valor* & $\begin{array}{l}\text { Razão de } \\
\text { Chances }\end{array}$ & Coeficiente & P-Valor* & $\begin{array}{l}\text { Razão de } \\
\text { Chances }\end{array}$ & Coeficiente & P-Valor* & $\begin{array}{l}\text { Razão de } \\
\text { Chances }\end{array}$ \\
\hline \multicolumn{2}{|r|}{ Intercepto } & 0,433 & 0,250 & 1,541 & 0,093 & 0,763 & 1,097 & 0,236 & 0,461 & 1,266 \\
\hline \multirow{4}{*}{ País } & Chile & $-0,096$ & 0,611 & 0,909 & 0,593 & 0,001 & 1,809 & 0,546 & 0,003 & 1,727 \\
\hline & Argentina & 1,222 & 0,000 & 3,394 & $-0,188$ & 0,312 & 0,828 & $-0,297$ & 0,123 & 0,743 \\
\hline & Uruguai & 1,130 & 0,000 & 3,097 & 1,116 & 0,000 & 3,053 & 1,108 & 0,000 & 3,029 \\
\hline & Brasil (Referência) & $0^{\mathrm{a}}$ & & 1,000 & $0^{\mathrm{a}}$ & & 1,000 & $0^{\mathrm{a}}$ & & 1,000 \\
\hline \multirow{3}{*}{ Idade } & até 29 anos & 0,637 & 0,002 & 1,890 & 0,573 & 0,005 & 1,774 & 0,588 & 0,004 & 1,801 \\
\hline & de 30 a 49 anos & 0,577 & 0,000 & 1,781 & 0,115 & 0,477 & 1,122 & 0,191 & 0,250 & 1,210 \\
\hline & 50 e mais (Referência) & $0^{\mathrm{a}}$ & & 1,000 & $0^{\mathrm{a}}$ & & 1,000 & $0^{\mathrm{a}}$ & & 1,000 \\
\hline \multirow{2}{*}{ Escolaridade } & Até o secundário & $-0,811$ & 0,000 & 0,444 & $-0,756$ & 0,000 & 0,469 & $-0,709$ & 0,000 & 0,492 \\
\hline & Secundário e mais (Referência) & $0^{\mathrm{a}}$ & & 1,000 & $0^{\mathrm{a}}$ & & 1,000 & $0^{\mathrm{a}}$ & & 1,000 \\
\hline \multirow[b]{2}{*}{ Decil de renda } & Até o $4^{\circ}$ decil & $-0,936$ & 0,000 & 0,392 & & & & $-0,253$ & 0,073 & 0,776 \\
\hline & do $5^{\circ}$ ao $10^{\circ}$ decil (Referência) & $0^{\mathrm{a}}$ & & 1,000 & & .. & & $0^{\mathrm{a}}$ & & 1,000 \\
\hline \multirow{2}{*}{ Religião } & Alguma religião & $-0,251$ & 0,100 & 0,778 & $-0,251$ & 0,074 & 0,778 & $-0,236$ & 0,101 & 0,790 \\
\hline & Sem religião (Referência) & $0^{\mathrm{a}}$ & & 1,000 & $0^{\mathrm{a}}$ & & 1,000 & $0^{\mathrm{a}}$ & & 1,000 \\
\hline \multirow{2}{*}{ Filhos } & Sem filhos & 0,475 & 0,026 & 1,608 & 0,049 & 0,812 & 1,050 & 0,030 & 0,885 & 1,030 \\
\hline & Com filhos (Referência) & $0^{\mathrm{a}}$ & & 1,000 & $0^{\mathrm{a}}$ & & 1,000 & $0^{\mathrm{a}}$ & & 1,000 \\
\hline \multirow{4}{*}{ Status Marital } & Casado & 0,154 & 0,425 & 1,166 & 0,003 & 0,986 & 1,003 & $-0,043$ & 0,835 & 0,958 \\
\hline & União consensual & 0,241 & 0,412 & 1,273 & $-0,131$ & 0,586 & 0,877 & $-0,157$ & 0,523 & 0,854 \\
\hline & Outro & $-0,095$ & 0,735 & 0,910 & 0,083 & 0,746 & 1,087 & 0,051 & 0,846 & 1,052 \\
\hline & Solteiro (Referência) & $0^{\mathrm{a}}$ & & 1,000 & $0^{\mathrm{a}}$ & & 1,000 & $0^{\mathrm{a}}$ & & 1,000 \\
\hline \multirow{3}{*}{ Aborto } & quase nunca/ nunca & 0,139 & 0,576 & 1,149 & $-0,411$ & 0,060 & 0,663 & $-0,466$ & 0,037 & 0,628 \\
\hline & alguma vez & 0,198 & 0,440 & 1,219 & $-0,295$ & 0,203 & 0,744 & $-0,297$ & 0,207 & 0,743 \\
\hline & quase sempre/sempre (Referência) & $0^{\mathrm{a}}$ & & 1,000 & $0^{\mathrm{a}}$ & & 1,000 & $0^{\mathrm{a}}$ & & 1,000 \\
\hline \multirow{3}{*}{$\begin{array}{l}\text { Homossexuali- } \\
\text { dade }\end{array}$} & quase nunca/ nunca & $-1,064$ & 0,000 & 0,345 & $-0,945$ & 0,000 & 0,389 & $-0,914$ & 0,000 & 0,401 \\
\hline & alguma vez & $-0,439$ & 0,032 & 0,645 & $-0,714$ & 0,000 & 0,490 & $-0,783$ & 0,000 & 0,457 \\
\hline & quase sempre/sempre (Referência) & $0^{\mathrm{a}}$ & & 1,000 & $0^{\mathrm{a}}$ & & 1,000 & $0^{\mathrm{a}}$ & & 1,000 \\
\hline \multirow{3}{*}{ Divórcio } & quase nunca/ nunca & $-0,242$ & 0,185 & 0,785 & 0,121 & 0,560 & 1,129 & 0,099 & 0,641 & 1,104 \\
\hline & alguma vez & 0,016 & 0,925 & 1,016 & 0,402 & 0,011 & 1,495 & 0,412 & 0,012 & 1,509 \\
\hline & quase sempre/sempre (Referência) & $0^{\mathrm{a}}$ & & 1,000 & $0^{\mathrm{a}}$ & & 1,000 & $0^{\mathrm{a}}$ & & 1,000 \\
\hline \multirow{2}{*}{$\begin{array}{c}\text { dona de casa }= \\
\text { assalariada }\end{array}$} & discorda (total ou parcialmente) & $-0,147$ & 0,261 & 0,863 & $-0,239$ & 0,067 & 0,787 & $-0,222$ & 0,096 & 0,801 \\
\hline & concorda (total ou parcialmente) (Referência) & $0^{\mathrm{a}}$ & & 1,000 & $0^{\mathrm{a}}$ & & 1,000 & $0^{\mathrm{a}}$ & & 1,000 \\
\hline
\end{tabular}

World Value Survey, ondas 3 (1995 - 1997), 5 (2006) e 6 (2011 - 2014). *Ao nível de significância de 90\%. Fonte: (Inglehart et al., 2014 a, b,c) - 


\section{Considerações Finais}

Ao analisar as informações da Pesquisa WVS em três diferentes momentos constatou-se que a proporção de indivíduos pós-materialistas ainda é muito baixa, e diminuiu ao longo dessas três pesquisas, chegando, na primeira metade da década de 2010, com o menor percentual. Ribeiro e Borba (2010, p. 30) já haviam chamado a atenção para esse fato, ao argumentarem que os países latino-americanos sofreram processos de modernização incompletos e frágeis em diferentes aspectos, daí não deterem as condições necessárias para fazerem parte do restrito grupo de nações pós-industriais. No entanto, os próprios autores afirmam que, apesar da baixa representatividade dos pós-materialistas na América Latina, os estudos envolvendo essa população são legítimos e podem trazer para debate aspectos importantes em diferentes dimensões da vida em sociedade.

Os resultados encontrados nesse estudo corroboram com essa perspectiva. Não obstante a redução na proporção de indivíduos pós-materialistas entre as três ondas WVS - acredita-se que tenha relação com o processo de modernização e com períodos de crise econômica e política dos países analisados, conforme já atestava Van Deth (1983) -, os dados encontrados indicam que o perfil de indivíduos materialistas e pós-materialistas é parecido com o que Inglehart descreve no estudo das sociedades mais avançadas. Apesar de as diferenças entre os perfis serem menores do que era esperado, com algumas variáveis não apresentando significância, os indivíduos pós-materialistas, de maneira geral, tendem a apresentar maior proporção de jovens, de elevada escolaridade e classe social, solteiros (ou vivendo em união consensual) e sem filhos, do que os indivíduos materialistas. E esse perfil mantém-se ao longo dos períodos de análise. Esses dados mostram que, de fato, somente uma parcela específica da sociedade encaixa-se no perfil pós-materialista, parcela esta para qual a satisfação das necessidades materiais básicas é garantida. E como esse grupo representa uma minoria da população dos países analisados, é justificável que o contingente pós-materialista seja pequeno nesses países.

Chamou a atenção, nesse estudo, a pouca expressividade do posicionamento dos indivíduos em relação ao aborto, ao divórcio e sobre a satisfação da mulher como dona de casa ou trabalhadora assalariada na determinação dos perfis. Esperava-se uma importância maior dessas variáveis para explicar as diferenças nas chances de um indivíduo ser materialista ou pósmaterialista. Mas isso não ocorreu em nenhuma das ondas WVS. Embora em alguns casos fosse significativo, o poder explicativo dessas variáveis não era considerável para distinguir os indivíduos segundo uma ou outra orientação valorativa. Apenas para a variável sobre homossexualidade é que o posicionamento do indivíduo tinha grande importância para diferenciar os grupos de materialistas e pós-materialistas. Esses resultados indicam que, para alguns temas, indivíduos pós-materialistas e materialistas podem dividir opiniões similares, seja no sentido de maior tolerância ou de menor aceitação. Um estudo mais aprofundado sobre esse ponto é necessário para entender melhor a interação entre posicionamento do indivíduo e seu perfil valorativo em países latino-americanos. Mas deve-se considerar, também, que a sociedade latino-americana está mudando muito lentamente o seu posicionamento, com alguns temas ainda permanecendo verdadeiros tabus. Certamente, as pessoas pós-materialistas estão na vanguarda dessa tendência, e, mesmo que de maneira lenta, poderá se estender para os materialistas, mas, por enquanto, as mudanças em curso ainda estão bastante longe de alcançar o nível de pós-modernidade dos países mais desenvolvidos.

Nesse sentido, acredita-se que os dados estão sinalizando para um processo ainda muito incipiente na América Latina e que parece ainda não ter se estabelecido de forma concreta, que é a difusão de valores e comportamentos pós-modernos. Contudo, pode ser que à medida que a população tiver maior acesso à educação formal, em que as minorias sociais alcançarem o seu espaço na sociedade, as relações de gênero tornarem-se mais equânimes tanto no ambiente macro quanto micro, o acesso às informações e aos meios de planejamento familiar atingir a todos os estratos populacionais, entre outras conquistas sociais e democráticas, a população tenderá a se tornar mais pós-materialista e, consequentemente, pós-moderna. Porém, esse processo deve ser pensado no longo prazo e que pode ocorrer de maneira truncada na Região, devido a questões culturais, políticas e econômicas que podem trazer certos retrocessos e tornar estes fenômenos diferentes dos moldes vivenciados pelos países desenvolvidos. Pois, assim como destacado por Oliveira (2012, p. 148), a região latino-americana, sendo marcada por 
"sociedades muito desiguais e com um mix significativo de origens culturais" não encontraria uma perfeita compatibilidade com uma teoria como a da Segunda Transição Demográfica (STD) de Lesthaeghe ou mesmo com a do pós-materialismo de Inglehart. Ou seja, vive-se na região um comportamento duo, e que, ao contrário dos países europeus, valores típicos da STD e do pósmaterialismo convivem lado a lado com valores tradicionais e conservadores.

Por fim, encoraja-se que novas pesquisas envolvendo a análise do pós-materialismo na região sejam realizadas, uma vez que foram disponibilizados, recentemente, para alguns dos países latino-americanos, os dados da última onda da WVS. Estes novos dados podem revelar novas dinâmicas sobre as tendências do pós-materialismo na região. Isso porque ocorreram várias mudanças importantes no contexto político recente de muitos países latino-americanos, como por exemplo o fato de que muitos se veem chefiados por governos de extrema direita, que, possivelmente, tendem a ter atuações no sentido de reduzir ou mesmo reverter as tendências de pós-materialismo observadas neste artigo.

\section{Agradecimentos}

Coordenação de Aperfeiçoamento de Pessoal de Nível Superior, CAPES pelo financiamento por meio da Bolsa de Pósdoutorado.

\section{Referências}

Birdsall, N. (2012) "A Note on the Middle Class in Latin America". Center for Global Delevopment, Working Paper 303, http://www.cgdev.org/content/publications/detail/1426386.

Bonifácio, G. M. de O. (2016) Evolução do padrão de fecundidade na América Latina: em busca de uma idiossincrasia. Tese (Doutorado em Demografia), Universidade Federal de Minas Gerais, Belo Horizonte.

Burni, A; Claret, A. \& Frahia, P. (2014) “Valores Pós-Materialistas e Democracia: Brasil e Uruguai em Perspectiva Comparada”. Em Debate,6(3), 60-82.

Cavenaghi, S M. \& Alves, J. E. D. (2009) "Fertility and contraception in Latin America: Historical trends, recent patterns", in Cavenaghi, S (ed.), Demographic Transformations and Inequalities in Latin America: Historical Trends and Recent Patterns. Rio de Janeiro, Asociación Latinoamericana de Población, pp. 161192.

Cavenaghi, S. M. \&; Alves, J E. D. (2013) “Childlessness in Brazil: socioeconomic and regional diversity”. Proceedings of XXVII IUSSP International Population Conference. Paris, IUSSP. vol. 1, pp. 1-25. https://iussp.org/sites/default/files/event_call_for_papers/ChildlessNessBrazil_Final.pdf.

Costa, C. de S. (2004) Uniões informais no Brasil em 2000: uma análise sob a ótica da mulher. Dissertação (Mestrado em Demografia), Universidade Federal de Minas Gerais, Belo Horizonte.

Da Silva, F. P. (2015) “Da onda rosa à era progressista: a hora do balanço”. SURES, 1(5), 67-94. https://ojs.unila.edu.br/ojs/index.php/sures,

Eklund, F. (2012) Consequences of post-materialism: Testing predicted changes and an extension to the Theory of Post-Materialism. Thesis (Bachelor in Political Science), Lund University, Lunda.

Esteve, A; Lesthaeghe, R \& López-Gay, A. (2012) “The Latin American Cohabitation Boom, 1970-2007”. Population and Development Review, 38(1), 55-81.

Holden, R. H. \&Villars, R. (2013) “Cap 15: The Family, Women and Sexuality”, in R. H. Holden e R. Villars, Contemporary Latin America: 1970 to the present. Chichester,John Wiley \& Sons, 281-304.

Hosmer, D. W. \& Lemeshow, S. (1989) Applied Logistic Regression. Wiley.

Ibarra, D. (2011) “O neoliberalismo na América Latina”. Revista de Economia Política, 31(2), 238-248.

IngleharT, R. (1990) Culture shift in advanced industrial society. Princeton, Princeton University Press.

Inglehart, R. (1997) Modernization and postmodernization: Cultural, economic, and political change in 43 societies. Princeton, Princeton university press.

Inglehart, R. (2000) “Globalization and postmodern values”. Washington Quarterly, 23(1), 215-228.

Inglehart, R. \& Baker, W E. (2000) "Modernization, cultural change, and the persistence of traditional values". American sociological review, 65(1), 19-51.

Inglehart, R \& Carballo, M. (2013) “Existe Latinoamérica?: Un análisis global de diferencias transculturales”, in M. Carballo e A. Moreno (coods.), El cambio de valores en America Latina: Hallazgos de La encuesta mundial de valores. Distrito Federal, Centro de Estudos de Opinião Pública, pp. 17-44.

Inglehart, R. \& Welzel, C. (2005) Modernization, cultural change, and democracy: the human development sequence. Cambridge University Press.

Inglehart, R. (1977) The Silent Revolution. Princeton, Princeton University Press. 
Inglehart, R Et al.(2014a) “World Values Survey: Round Three-Country-Pooled Datafile 1995-1998”. JD Systems Institute, [12-09-2018]. http://www.worldvaluessurvey.org/WVSDocumentationWV.

Inglehart, R et al.(2014b) "World Values Survey: Round Five-Country-Pooled Datafile 2005-2008". JD Systems Institute, [12-09-2018]. http://www.worldvaluessurvey.org/WVSDocumentationWV.

Inglehart, R et al.(2014c) "World Values Survey: Round Six-Country-Pooled Datafile 2010-2014". JD Systems Institute, [12-09-2018]. http://www.Worldvaluessurvey.Org/WVSDocumentationWV.

Larraín, J. (2004) “Cap. 2: Modernity and identity: cultural change in Latin America”, in R. N. Gwynne and K. A. Y. Cristobal, (eds.). Latin America transformed: globalization and modernity. Oxford, Oxford University Press, pp. 22-38.

Larrañaga, O. (2010) "El Estado de Bienestar en Chile: 1910-2010". Documento de Trabajo, Programa de las Naciones Unidas para el Desarrollo (PNUD) y Universidad De Chile, 2.

Lesthaeghe, R. (2014) “The second demographic transition: A concise overview of its development”.Política Nacional de Assistência Social, 51,111:pp.1811218115.

Macintosh, R. (1998), “Global attitude measurement: An assessment of the world values survey postmaterialism scale”. American Sociological Review, 63(3), $452-464$.

Machado, D. F. \& Graupe, M. E. (2016) “As Políticas Públicas LGBTTT no Campo Educacional: Avanços ou Retrocessos?”. Revista Universidade do Planalto Catarinense - Anais da XIX Mostra Científica, 4(1).1-15.

Miguel, L F.; Biroli, F \& Mariano, R. (2017) "O direito ao aborto no debate legislativo brasileiro: a ofensiva conservadora na Câmara dos Deputados". Opinião Pública,23(1): 230-260.

Musa, A. (2006) "Was There a Silent Revolution? A Comparative Analysis of Party Manifestos in Ten European Countries". Politička misao:časopis za politologiju,43(5): 121-146.

Nathan, M., Pardo, I. \& Cabella, W. (2016) “Diverging patterns of fertility decline in Uruguay”. Demographic Research, 34(20): 563-586.

Oliveira, M. C. (2012) “A segunda transição demográfica: nova teoria ou mais do mesmo?”, in E. Berquó; S. Garcia; M. C. Oliveira e M. Livi-Bacci (orgs.). Segunda transição demográfica no Brasil? Significados e enigmas. Demografia em Debate, 4, 135-156.

Okado, L. T. A. \& Ribeiro, E A. (2017) "Mudança de valores em países latino-americanos: comparando os índices de pós-materialismo e valores

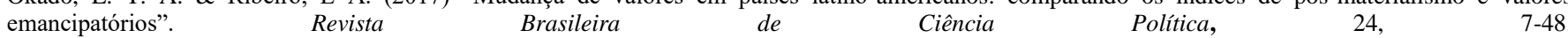
http://www.scielo.br/scielo.php?pid=S010333522017000300007\&script=sci_abstract\&tlng=pt,

Pinheiro, A. C. \&Giambiagi, F. (1999) “O Desempenho Macroeconômico do Brasil nos Anos 90”, in: F. Giambiagi e M. M. Moreira (org.), A economia brasileira nos anos 90. Rio de Janeiro, Banco Nacional de Desenvolvimento Econômico e Social, pp. 13-41.

Ribeiro, E A. (2007) "A consistência das medidas de pós-materialismo: testando a validade dos índices propostos por R. Inglehart no contexto brasileiro". Sociedade e Estado, 22(2), 371-400.

Ribeiro, E A. (2009) "Mudança de valores e tolerância entre os brasileiros”. Mediações, 15(1), 220-240.

Ribeiro, E A.\& Borba, J. (2010) "Participação e pós-materialismo na América Latina”. Opinião Pública, 16(1)28-64.

Rocha, R. O.; Siqueira, G. C. B. \& Aarão, B. De F. C. (2014) "Mudanças de valores, materialismo e pós-materialismo: algumas ponderações sobre o Cone Sul”, in Anais do V Congresso Uruguayo de Ciencia Política, Montevideo.

Sader, E. (2006) “América Latina en el siglo XXI”, in A. Boron y G. Lechini (orgs.), Política y movimientos sociales en un mundo hegemónico. Lecciones desde África, Asia y América Latina. Buenos Aires, Consejo Latinoamericano de Ciencias Sociales, pp. 51-80.

Salvia, A. \& Tissera, S. (2002) "Heterogeneidad y precarización de los hogares asalariados en la Argentina durante la decada del '90". Ecuador Debate. Los mundos de la familia, (56), 109-126.

Sola, L. (1995) "Estado, Regime Fiscal e Ordem Monetária: Qual Estado?", in L. Sola e L. M. Paulani (orgs.), Lições da Década de 80. Editora da USP, 2960 .

Surkyn, J. \& Lesthaeghe, R. (2004) "Value orientations and the second demographic transition (SDT) in Northern, Western and Southern Europe: An update". Demographic research, special collection,3: 45-86.

Van De Kaa, D. J. (2001) "Postmodern fertility preferences: From changing value orientation to new behavior". Population and Development Review, 27, Supplement: Global Fertility Transition, 290-331.

Van De Kaa, D. J. (1987) “Europe’s Second DemographicTransition”. Population Bulletin, 42(1), 1-55.

Van Deth, J. W. (1983) “The persistence of materialist and post-materialist value orientations”. European Journal of Political Research, 11(1), 63-79.

Vigorito, A. (1999) “La distribución del ingreso en Uruguay entre 1986 y 1997”. Revista de Economía, 6(2), 243-300.

Wong, L L. R.\& Bonifácio, G M. de O. (2009) "Retomada da queda da fecundidade na América Latina. Evidências para a primeira década do século XXI". Revista Latinoamericana de Población, 3(4-5): 93-1. 